\title{
ABORDAGENS TEÓRICAS E METODOLÓGICAS DO GRUPO DE PESQUISA EM EDUCAÇÃO AMBIENTAL DA UFES: ESTUDOS DESDE A COMPLEXIDADE
}

\author{
Martha Tristão
}

Resumo: O Núcleo Interdisciplinar de Pesquisa e Estudo em Educação Ambiental (NIPEEA) emerge da necessidade de integração entre projetos e pesquisas em Educação Ambiental envolvendo ensino, pesquisa e extensão, com vistas à consolidação de um grupo vinculado ao Programa de Pós-Graduação e ao Centro de Educação da UFES. Os objetivos do grupo são: integrar pesquisas realizadas nos níveis de mestrado, doutorado e projetos de ensino, pesquisa e extensão e constituir um Centro de Referência de abordagem interdisciplinar e transdisciplinar em Educação Ambiental. As problemáticas das pesquisas se coadunam com a emergência de um paradigma sustentável e de uma racionalidade mais aberta e com os pressupostos de que sujeito e objeto são indissociáveis, a realidade é compreendida a partir de níveis relacionados com as percepções dos sujeitos e as conclusões das pesquisas serão sempre parciais e relativas, pois é impossível compreender e abarcar toda a complexidade socioambiental da realidade pesquisada.

Palavras-chave: Transdisciplinaridade. Racionalidades. Complexidade.

Abstract: The Center for Interdisciplinary Research and Environmental Education (NIPEEA, Portuguese acronym) emerged in response to the needs of integration between the projects and the research studies carried out on environmental education involving teaching, research and extension, aiming at the consolidation of a group associated with the Graduate Program and the Faculty of Education of the Federal University of Espírito Santo (UFES). The group's goals are: to provide a link between Master's and Doctor's degrees studies and teaching, research and extension projects and to build a Reference Center for interdisciplinary and transdisciplinary approaches in Environmental Education. The research problems are consistent with an emerging sustainable paradigm and a more open rationality that assumes that subject and object are inseparable, reality is understood based on different levels related to the perceptions of an individual, and research findings are always partial and relative, as it is impossible to understand and embrace the full complexity of the social and environmental realities studied.

Keywords: Transdisciplinarity. Rationality. Complexity.

1 Coordenadora do Núcleo Interdisciplinar de Pesquisa e Estudo em Educação Ambiental (NIPEEA) da Universidade Federal do Espírito Santo 


\section{Sobre o Grupo:}

A proposta de criação do Núcleo Interdisciplinar de Pesquisa e Estudo em Educação Ambiental - NIPEEA emerge da necessidade de integração entre projetos e pesquisas em Educação Ambiental que envolve ensino, pesquisa e extensão, com vistas a consolidação de um grupo formado por professores, alunas e alunos dos cursos de graduação, do Mestrado e Doutorado em Educação do Programa de Pós-Graduação do Centro de Educação da UFES e de egressos/as interessados/as.

Com a constituição do grupo em 2005, cria-se um espaço de continuidade de pesquisas já realizadas, de novos projetos de pesquisas sobre a Educação Ambiental em contextos escolares e não escolares de aprendizagens e de formação. Assim, dentre os objetivos do grupo destacam-se a possibilidade de: integrar pesquisas realizadas em níveis de mestrado, doutorado e de projetos de ensino, pesquisa e extensão; constituir um Centro de Referência de abordagem interdisciplinar e transdisciplinar em Educação Ambiental e criar um acervo com intuito de oferecer maiores informações, teorias e fontes de pesquisa para a comunidade universitária*.

Nosso movimento hoje se organiza a partir de ações bem diversificadas, estabelecendo uma unidade entre os participantes ao nos inserirmos em projetos de pesquisas, processos de formação em Educação Ambiental e no engajamento político que potencializa e fortalece o grupo. Assim realizamos: promoção de seminários entre pesquisadores/as para debates teóricos e discussão das pesquisas em curso, realização de encontros estaduais de Educação Ambiental, organização e elaboração de Anais, atuação em disciplinas na graduação e na pós-graduação, participação na formulação e implementação de políticas públicas, atuação na organização em redes - Rede Brasileira de Educação Ambiental/REBEA e Rede Capixaba de Educação Ambiental/RECEA e, mais recentemente integramos a Rede de Formação para a diversidade na elaboração de materiais didáticos e na promoção de um Curso de Atualização em Educação Ambiental a distância, junto à Secretaria de Educação Continuada Alfabetização e Diversidade do Ministério da Educação e Cultura - SECAD/MEC. Além disso, dialogamos formalmente com pesquisadores do TEIA, grupo de pesquisa em Educação Ambiental da USP, do GPEA - Grupo Pesquisador em Educação Ambiental da UFMTe do Grupo Cultura, ambiente e educação da PUCRS.

As pesquisas desenvolvidas pelo NIPEEA em níveis de mestrado e doutorado estão inseridas na Linha de Cultura, Currículo e Formação de educadores do Programa de Pós-Graduação em Educação da UFES, cuja proposição em sua ementa é a de abranger questões relacionadas com o currículo e com o processo de formação de educadores e educadoras em suas dimensões sócio-histórica e socioambiental. 


\section{Abordagens epistemológicas}

Acreditamos, como alguns autores, que não estamos vivendo momentos nem de ruptura nem de continuidade cronológica com o paradigma moderno ou pós-moderno. Estamos no movimento entre conflitos e contradições, entre um pensamento e outro, já que vivemos em ambos ruptura e continuidade. Dialogamos com autores que consideram essa era como pós-moderna, marcada pela imprevisibilidade, pela rapidez, pela realidade virtual, pela cultura televisiva e por uma linguagem imagética.

Com relação a uma interpretação da Educação Ambiental nessa contemporaneidade, construímos aportes a partir de referenciais que possam ampliar nosso repertório argumentativo nesse processo civilizatório, seja considerado pós-moderno, modernidade tardia, supermodernidade (Marc Augé) ou modernidade líquida (Bauman). O que nos marca é a emergência de um paradigma e de uma racionalidade mais aberta que nos possibilita entender a interdependência entre ciência, culturas, sociedades, educação e escolas comprometidas com uma formação ambiental com a sustentabilidade do planeta.

Partimos do pressuposto de que a Educação Ambiental tem se configurado como uma dimensão educativa transdisciplinar que abarca características muito próprias, relacionadas à reflexão e às mudanças de uma racionalidade utilitarista e funcional e do binarismo das relações sociedade e meio ambiente, cultura e natureza, teoria e prática, local/global e tempo/espaço. Nossos diálogos ocorrem com autores provocadores de outras racionalidades e que possibilitam o entendimento de nossos objetos de pesquisa. Defendemos uma racionalidade mais aberta para a formação de um espírito de comunidade e de uma identidade coletiva.

Neste sentido, fazemos uma ponte suspensa, de um caminho não-linear com o pensamento do sociólogo Boaventura de Souza Santos que, para combater a racionalidade de uma única via, de mão única, de uma razão indolente nos fala de uma sociologia das ausências para a compreensão de realidades não-existentes, invisíveis, não - criveis que cria monoculturas. Uma delas é a monocultura do saber, do rigor que considera como única forma de conhecimento rigoroso, o saber científico. Como proposta usamos do autor a metáfora da ecologia dos saberes, não para ver como o conhecimento representa, reproduz ou reflete o real, mas como determinado conhecimento produz na realidade. Quais racionalidades vêm sido produzidas pelas práticas culturais e sustentáveis em processos contra-hegemônicos?

A lógica instrumental clássica desencadeou uma clara divisão entre a evolução cultural humana e os processos naturais e ambientais, pautada na acumulação e na exclusão. A defesa pelo meio ambiente emerge como movimento de resistência ao pensamento capitalista moderno. A mais grave conseqüência e prejuízo dessa racionalidade irracional é a degradação social e ambiental.

A lógica da acumulação invade o mundo e parece ser o grande fator desencadeador da separação entre razão e emoção. Nesse caso, emergem outras 
lógicas, a lógica da emoção, do sentir. Com isso, não propomos nenhuma superação das contradições. O pensamento complexo diz que não podemos superar as contradições e, muito menos, deixá-las de lado. Nesse caso, razão e emoção convivem no entrelaçamento da constituição do ser humano, pois, como diz Maturana (1998), qualquer sistema racional tem um fundamento emocional.

Para tanto, dialogamos estreitamente para citar apenas alguns, com autores como Morin que convida-nos a pensar a complexidade desse tempo, com Michel de Certeau sobre as práticas políticas e sociais cotidianas com seu entendimento do espaço como lugar praticado, com Maturana e com Mafessoli, o primeiro com seu conceito de autopoiese, sendo ambos com propostas de uma razão mais sensível, mais emocionada. Quanto aos processos homogeneizantes e globalizadores da cultura, o pressuposto é o de que existem formação de novas identificações culturais. $O$ autor que nos ajuda a compreender a diáspora cultural da globalização é Stuart Hall.

Stuart Hall argumenta que há um interesse pelo local. Esse local, como sugere, não pode ser pensado como identidades enraizadas e definidas em localidades delimitadas, com uma unificação da cultura, esse local tem uma relação permanente com o global. A globalização não vai simplesmente destruir as identidades nacionais ou locais, é provável que esse processo, então, reconduza a novas identificações globais e a novas identificaçôes locais (Hall, 1997). Neste sentido, nossas pesquisas estão interessadas em traduzir essas novas identificações socioambientais. Mas que tradução estamos falando? Conseguimos captar o real ou somente a sua projeção? Nesse sentido atribuímos significados ao que captamos. De fato, problematizamos nossos objetos de pesquisa, mais do que necessariamente procuramos soluções.

Como pano de fundo das abordagens que trazemos para a compreensão da pesquisa em Educação Ambiental, a complexidade nos ajuda a respeitar o diverso e, ao mesmo tempo aceita o uno, ou seja, tenta discernir as interdependências: de um pensamento radical (raiz do problema); de um pensamento multidimensional; de um pensamento organizador ou sistêmico que compreenda as inter-relações e interações - base das ciências ecológicas e das ciências da Terra; de um pensamento ecologizado que não isola o objeto de estudo, mas o considera na sua relação auto-eco-organizadora com seu meio ambiente cultural, social, econômico, político e natural; de um pensamento que percebe a ecologia da ação e de um pensamento que reconheça seu inacabamento e negocie com a incerteza, sobretudo na ação (Morin, 2000).

$\mathrm{Na}$ tentativa de associar a vida com o conhecimento e o conhecimento como vida, os fundamentos de uma metodologia de pesquisa passam a ser compreendidos como espaços de enredamentos. Essa abordagem considera a subjetividade, as relações intersubjetivas e a fundamentação como um conhecimento não-linear, fazendo analogia com a metáfora da rede para compreender a vida e o conhecimento, expressando o sentido de entrelaçamento e de interdependência. 
A ênfase na formação em Educação Ambiental, então, passa a ser compreendida como uma rede de contextos que, desde a formação inicial, estendendo-se à vivência, à atuação profissional, a política, a pesquisa, a militância e à participação em cursos, grupos e eventos, são compreendidos como espaços/tempos de formação. Com isso, não desresponsabilizamos as principais entidades formadoras do compromisso com a formação ambiental.

A formação; parece seguir a fragmentação da educação, definida como atuação das gerações adultas sobre a dos jovens para ficar coextensiva à vida, o que nos remete a pensar em uma formação permanente. A formação, hoje, impõe-se como uma função vital a ser permanentemente exercida.

Essa concepção já traz implícito um processo educativo e formativo que envolve uma reforma do pensamento e das estruturas. Os caminhos e as idéias tornam-se desafiantes e imprecisos, envolvendo a complexidade da Educação Ambiental e de seus contextos. O pensamento de Morin é bastante expressivo dessa tendência pós-crítica, embora alguns autores o associem à tendência crítica, o que é compatível com o pensamento complexo que nos propõe trabalhar com aspectos complementares, concorrentes e antagônicos ao mesmo tempo. Sugere, também, não tentar superar as contradições, mas reconhecê-las, ou seja, sair do pensamento de uma só via ou alternativa. Essa maneira de pensar a pesquisa, a educação e a formação envolve o pessoal e se mistura com o teórico, num movimento permanente e contínuo, recursivo do processo permanente de formação.

O pensamento transdisciplinar inscreve-se nesta perspectiva de abertura, pois pode ser compreendido como um princípio epistemológico que se apresenta em uma dinâmica processual que tenta superar as barreiras do conhecimento mediante a integração de conceitos e metodologias. Optamos por compreender a transdiciplinaridade por entendê-la como uma abordagem que transcende as disciplinas, que tenta entender o que está além. E, para nós a Educação Ambiental preenche este espaço entre, através e além das disciplinas. Para Nicolescu, um dos cientistas que atuam nesta área, a condição de princípio epistemológico da transdisciplinaridade depende das relações entre três axiomas: os níveis de realidade, ou seja, a realidade pode ser a de um mundo macrofisico e de um mundo microfisíco, hoje já temos uma outra realidade que é a virutual, a lógica do terceiro incluído quer dizer que entre pólos contraditórios ocorrem tensões que promove uma unidade mais ampla e, por fim, a complexidade. Em nossas pesquisas, essa lógica nos favorece a compreensão de um mundo imaginário, de outras percepções ligadas ao nível de realidade dos símbolos, dos mitos e do sagrado.

\section{Pressupostos teóricos e metodológicas das pesquisas}

Os direcionamentos metodológicos das pesquisas são delineados ao longo de seu processo, pois, entendemos como Morin que: 
[...] Temos de aceitar caminhar sem caminho, fazer o caminho no caminhar. $O$ que dizia Machado Caminhante no hay camino, se hace caminho al andar. $O$ método só pode formar-se durante a investigação; só pode desprender-se e formular-se depois no momento em que o termo se torna um novo ponto de partida desta vez dotado de método [..].O regresso ao começo não é um círculo vicioso se a viagem, como hoje a palavra trip indica, significa a experiência donde se volta mudado. (MORIN, 1997, p.25).

Assim nos situamos em uma proposta metodológica para além da categorização dos dados, tentamos não classificar para não reduzir o universo pesquisado, garantir a sua integridade e compreender os processos identitários. Tratamos de compreender o sentido interpretativo atribuído as narrativas dos sujeitos narradores, co-participantes de nossas problemáticas investigativas. Se é assim, torna-se muito importante as histórias que escutamos e lemos, o funcionamento dessas histórias no interior de práticas sociais e sustentáveis, das experiências mais ou menos institucionalizada ou não, como as práticas pedagógicas (Larrosa, 2002).

Tratamos, também, essa interpretação de acordo com o pensamento de Larrosa (2003, p. 41), quando diz que

[...] é contando nossas próprias histórias que damos a nós mesmos, uma identidade. Reconhecemo-nos, a nós mesmos, nas histórias que contamos sobre nós mesmos. E é pequena a diferença se essas histórias são verdadeiras ou falsas, tanto a ficção, como a história verificável, nos provêm de uma identidade.

Em sintonia com esta perspectiva levantada, nossas problemáticas de pesquisa se coadunam com alguns pressupostos que nos apontam caminhos metodológicos compatíveis com nossos referenciais teóricos.

Consideramos sujeito-objeto como indissociáveis e tentamos superar a idéia da pesquisa convencional e clássica do necessário distanciamento para garantir a confiabilidade da pesquisa; a realidade é compreendida a partir de níveis de realidades relacionados com as percepções dos sujeitos o que nos permitirá, fazermos aproximações pois muitos fios tecidos das redes vividas ficarão invisíveis; as conclusões das pesquisas serão sempre parciais e relativas, pois é impossível compreender e abarcar toda a complexidade da realidade pesquisada.

Consideramos, também, que as imagens ampliam a possibilidade de compreensão narrativa da realidade cotidiana porque carregam elementos sensíveis que nem sempre o texto escrito ou oral consegue captar e traduzir. A imagem, para nós não está dissociada de outras formas de expressão da realidade, 
não é apenas representativa, mas compõe significados para a compreensão narrativa.

Consideramos os múltiplos espaçostempos do cotidiano escolar e não escolar e as articulações entre eles. Dessa forma, temos possibilidade de recorrer num hibrido metodológico a fenomenologia, ao biorregionalismo, a história oral e, mais recentemente, a pesquisa cartográfica.

\section{Referências}

HALL, Stuart._Identidades culturais na pós-modernidade. Rio de Janeiro: DP\&A, 1997.

MATURANA, Humberto. Emoções e linguagem na educação e na política. Belo Horizonte: Editora UFMG, 1998.

SANTOS, Boventura de Souza. Renovar a teoria crítica e reinventar a emancipação social. São Paulo: Boitempo, 2007.

MORIN, Edgar; KERN, Anne Brigitte. Terra-Pátria. Porto Alegre: Sulina, 2000.

MORIN, Edgar. O método: a natureza da natureza. 3. ed. Portugal: Publicações EuropaAmérica Ltda., 1997.

LAROSSA, Jorge. Pedagogia profana: danças, piruetas e mascaradas. 4. ed. Tradução de Alfredo Veiga-Neto. Belo Horizonte: Autêntica, 2003.

LARROSA, Jorge. Leitura, experiência e formação: uma entrevista de Jorge Larrosa. In: VORRABER, Marisa Costa (Org). Caminhos Investigativos: novos olhares na pesquisa em educação. 2. ed. Rio de Janeiro: DP\&A, 2002.

Artigo recebido em 20/08/2010 - a aprovado em 17/12/2010 